\title{
Türk toplumundaki yașlı erkeklerde ișeme pozisyonunun ișeme sonrası rezidüel idrar hacmi üzerine etkisi
}

\author{
The effect of voiding position on post-voiding residue in aging men in \\ turkish society
}

\author{
Cavit Ceylan®, Șenol Tonyalı๑, Serkan Doğan®, Sedat Yahși®, Emre Uzun®
}

\section{öz}

AMAC:: Türk toplumundaki erkeklerde işeme pozisyonunun ișeme sonrası idrar miktarı [post-voiding rezidü (PVR)] üzerine etkisini araştırmak. GEREÇ ve YÖNTEM: 2017-2018 yıllarında alt üriner sistem semptomu (AÜSS) ile polikliniğe başvuran ve PSA yüksekliği nedeni ile ultrasonografi eşliğinde transrektal iğne biyopsisi (TRİB) planlanan hastalar çalışmaya dahil edildi. Hastaların demografik bilgileri, üroflowmetri parametreleri [maksimum idrar akım hızı (Q max), ortalama idrar akım hızı (Q ortalama), transrektal ultrasonografide prostat hacimleri ve PVR değerleri kayıt edildi. Hastalar işeme alışkanlığına göre iki gruba ayrıldı: Grup 1=Ayakta işeme alışkanlığı olan hastalar; Grup 2=Çömelerek işeme alışkanlığı olan hastalar.

BULGULAR: Çalışmaya toplam 88 hasta dahil edildi. İki grubun karşılaştırılmasında sırasıyla PSA düzeyleri, prostat hacimleri, üroflowmetride işenen hacim, Q max, Q ort ve PVR açısından anlamlı fark saptanma$\mathrm{d}_{1}(\mathrm{p}=0,993, \mathrm{p}=0,887, \mathrm{p}=0,449, \mathrm{p}=0,093, \mathrm{P}=0,209, \mathrm{p}=0,063)$. Yaş ve prostat hacmi ile PVR arasında istatiksel olarak güçlü bir korelasyon gösterildi $(\mathrm{p}<0,001, \mathrm{p}<0,001)$.

SONUÇ: Yaşlı Türk erkek popülasyonunda ayakta ve çömelerek işemenin ișeme sonrası mesanede kalan idrar hacmi üzerine herhangi bir etkisinin olmadı̆̆ı gösterilmiştir.

Anahtar Kelimeler: ayakta işeme, çömelerek işeme, post-voiding rezidü, benign prostat hiperplazisi

\section{GíRiș}

Mesanenin, üreterlerden gelen idrarı depolamak ve işeme sırasında idrarı dışarı atmak olmak üzere birbirini tamamlayan iki işlevi bulunmaktadır. İşeme esnasında intravezikal basınç artar, çıkım direnci azalır ve mesane boşaltılır.

Sağlık Bilimleri Üniversitesi, Türkiye Yüksek Ihtisas Eğitim ve Araştırma Hastanesi, Üroloji Kliniği, Ankara, Türkiye

\section{Yazıșma Adresi/ Correspondence:}

Doç. Dr. Cavit Ceylan

Türkiye Yüksek Ihtisas Eğitim ve Araştırma Hastanesi, Üroloji Kliniği 06230

Ankara, Türkiye

Tel. $\quad$ +905065421569

E-mail: ceylancavit@yahoo.com

Geliş/ Received: $\quad$ 21.01.2019

Kabul/ Accepted: 14.03 .2019

\section{ABSTRACT}

OBJECTIVES: To investigate the effect of voiding position on postvoiding residue (PVR) in male Turkish population.

MATERIAL and METHODS: Patients who were admitted to the outpatient clinic with lower urinary tract symptoms (LUTS) in 2017-2018 and who were scheduled for ultrasound-guided transrectal needle biopsy (TRIB) due to PSA elevation were included in the study. Demographic information, uroflowmetry parameters [maximal urinary flow rate $(\mathrm{Q}$ max), mean urinary flow rate ( $Q$ mean)], prostate volumes in transrectal ultrasound were recorded. The patients were divided into two groups according to their habit of voiding: Group 1=Patients voiding at standing-up position; Group 2=Patients voiding at squatting position. RESULTS: A total of 88 patients were included in the study. No significant difference was found between the two groups in terms of PSA levels, prostate volumes, voided volume, Q max, Q average and PVR $(\mathrm{p}=0.993, \mathrm{p}=0.887, \mathrm{p}=0.449, \mathrm{p}=0.093, \mathrm{P}=0.209, \mathrm{p}=0.063)$. There was a statistically significant correlation between age and prostate volume and PVR $(\mathrm{p}<0.001, \mathrm{p}<0.001)$.

CONCLUSION: It has been shown that voiding at standing or squatting position has no effect on post-voiding residual urine volume in elderly Turkish male population.

Keywords: standing voiding, squatting voiding, post-voiding residue, benign prostate hyperplasia

İntravezikal basınç sakral kordda yerleşik spinal refleks ile detrüsör kasının kasılması ile arttırılır. Bu refleks beyindeki üst merkezlerinin kontrolü altındadır ve istemli olarak başlatılabilir veya inhibe edilebilir. ${ }^{[1]}$

Üretranın proksimal kısmı hem kadında hem erkekte belirgin bir distal sfinkter, iskelet kası tabakası (intrinsik rabdosfinkter) ve bir pubo-üretral kas askısı içerir. Fakat, üretranın toplam uzunluğu erkeklerde kadınlardakinden belirgin olarak fazladır (yaklaşık $20 \mathrm{~cm}$ 'e karşın $4 \mathrm{~cm}$ ). Bu durum erkeklerde idrar akımı karşısında bariz bir direnç oluşturur. ${ }^{[2]}$ İşeme pozisyonunun ürodinamik parametreleri etkileyerek işeme üzerine etkileri olabileceği düşünülmüş ve bu konuda sınırlı sayıda olsa da pek çok çalışma dizayn edilmiştir. ${ }^{[3-6]}$ 
Yaşlanan erkek popülasyonunda ürolojik olan ve olmayan pek çok faktör alt üriner sistem semptomlarına (AÜSS) neden olabilir. Yaş ile birlikte mesanede ve nörolojik fonksiyonlarda değişiklikler meydana gelebilir. ${ }^{[7]}$

BPH'ya bağlı mesane çıkım obstrüksiyonunun kesin değerlendirmesinde basınç akım testi kullanılır. Fakat invaziv ve pahalı bir tetkik olduğu için klinik pratikte serbest üroflowmetri, işeme sonrası mesanede kalan idrar miktarı [post-voiding rezidü (PVR)] ve prostat hacmi ölçümü kullanilir. ${ }^{[8]}$

Biz bu çalışmamızda, Türk toplumundaki erkeklerde işeme pozisyonunun PVR üzerine etkisini araştırarak, benign prostat hiperplazisi olan hastaların üst üriner sistemlerinin korunmasında işeme pozisyonunun etkisi olup olmayacağını ortaya koymayı ve benign prostat hiperplazisi için gereksiz operasyonların önüne geçebilmeyi amaçladık.

\section{GEREÇ VE YÖNTEM}

Hastanemiz eğitim ve planlama kurulu onayı alındıktan sonra 2017-2018 yıllarında AÜSS ile polikliniğe başvuran ve PSA yüksekliği nedeni ile ultrasonografi eşliğinde transrektal iğne biyopsisi (TRİB) planlanan hastalar çalışmaya dahil edildi. Hastaların demografik bilgileri, üroflowmetri parametreleri [maksimum idrar akım hızı $(\mathrm{Q}$ max), ortalama idrar akım hızı (Q ortalama), transrektal ultrasonografide prostat hacimleri ve PVR değerleri kayıt edildi. PVR ultrason eşliğinde suprapubik olarak ölçüldü. Çalışmaya mesaneye indante prostat medyan lobu olanlar, mesane içinde taş, double J-stent (DJS) veya tümörü olanlar, üriner sistem enfeksiyonu olanlar, nörojenik mesane, diyabet veya kronik obstrüktif akciğer hastalığ $(\mathrm{KOAH})$ tanısı olanlar, akut idrar retansiyonu öyküsü olanlar ile ciddi ortopedik problemi olan hastalar çalışmadan dışlandı.

Hastalar işeme alışkanlığına göre iki gruba ayrıldı: Grup1=Ayakta durarak işeme alışkanlığı olan hastalar; Grup 2=Alaturka tuvalet tipinde çömelerek işeme alışkanlığı olan hastalar.

Hastaların ayakta yapılan üroflowmetride ölçülen işeme hacmi, maksimum işeme hızları (Q max), ortalama işeme hızları (Q ortalama) karşılaştırıldı. Çömelerek işeme alışkanlığı olan hastaların çömelerek işeme sonrası rezidü idrar hacimleri ölçüldü ve iki grubun PVR değerleri karşılaştırıldı.

Verilerin istatistiksel analizinde IBM SPSS statistics for Mac versiyon 21 (Chicago, IL, USA) kullanılmıştır. Sürekli değişkenler ortalama \pm standart sapma olarak verilirken, kategorik değişkenler sayılar ve yüzdeler olarak verilmiştir. Verilerin normal dağılıp dağılmadığı test etmek için Kolmogorov-Smirnov testi kullanılmıştır. Sürekli değişkenlerin korelasyon testi için Pearson's test, farklı grupların karşılaştırılmasında Student's t testi kullanılmıştır. $\mathrm{p}<0,05$ istatistiksel olarak anlamlı kabul edilmiştir.

\section{BULGULAR}

Çalışmaya toplam 88 hasta dahil edildi. Grup1 ve Grup $244^{\prime}$ 'er hasta içeriyordu. Grup 1'in yaş ortalaması $66,3 \pm 6,5$ yıl iken Grup 2'nin yaş ortalaması $65,5 \pm 8,8$ y1l idi ve aralarında istatistiksel anlamlı fark saptanma$\mathrm{d}_{1}(\mathrm{p}=0,608)$. İki grubun karşılaştırılmasında sırasıyla PSA düzeyleri, prostat hacimleri, üroflowmetride işenen hacim, Q max, Q ort ve PVR açısından anlamlı fark saptanmad $(\mathrm{p}=0,993, \mathrm{p}=0,887, \mathrm{p}=0,449, \mathrm{p}=0,093$, $\mathrm{P}=0,209, \mathrm{p}=0,063$ ) (Tablo 1.)

Pearson korelasyon testi ile değerlendirildiğinde yaş ve prostat hacmi ile PVR arasında istatiksel olarak güçlü bir ilişki gösterildi ( $<<0,001, \mathrm{p}<0,001)$. (Şekil 1 ve 2$)$

Tablo 1. Ayakta ve çömelerek işeme alışkanlığı olan hasta gruplarının karşılaştırılması

\begin{tabular}{lccc}
\hline & Grup 1 & Grup 2 & P değeri \\
\hline Yaş (yll) & $66,34 \pm 6,51$ & $65,50 \pm 8,68$ & 0,608 \\
PSA (ng/dl) & $11,87 \pm 13,23$ & $11,85 \pm 8,71$ & 0,993 \\
Prostat Hacmi (cc) & $67,16 \pm 31,06$ & $68,09 \pm 30,22$ & 0,887 \\
İşenen Hacmi (ml) & $182,45 \pm 49,03$ & $176,66 \pm 12,36$ & 0,449 \\
Q max (ml/sn) & $14,14 \pm 2,64$ & $13,26 \pm 2,20$ & 0,093 \\
Q ort (ml/sn) & $9,35 \pm 2,08$ & $8,83 \pm 1,75$ & 0,209 \\
PVR (ml) & $62,75 \pm 18,94$ & $71,84 \pm 25,75$ & 0,063 \\
\hline
\end{tabular}

Q max: üroflowmetrideki maksimum idrar akış hızı, Q ort: üroflowmetrideki ortalama idrar akış hızı, PVR: post-voiding rezidü.

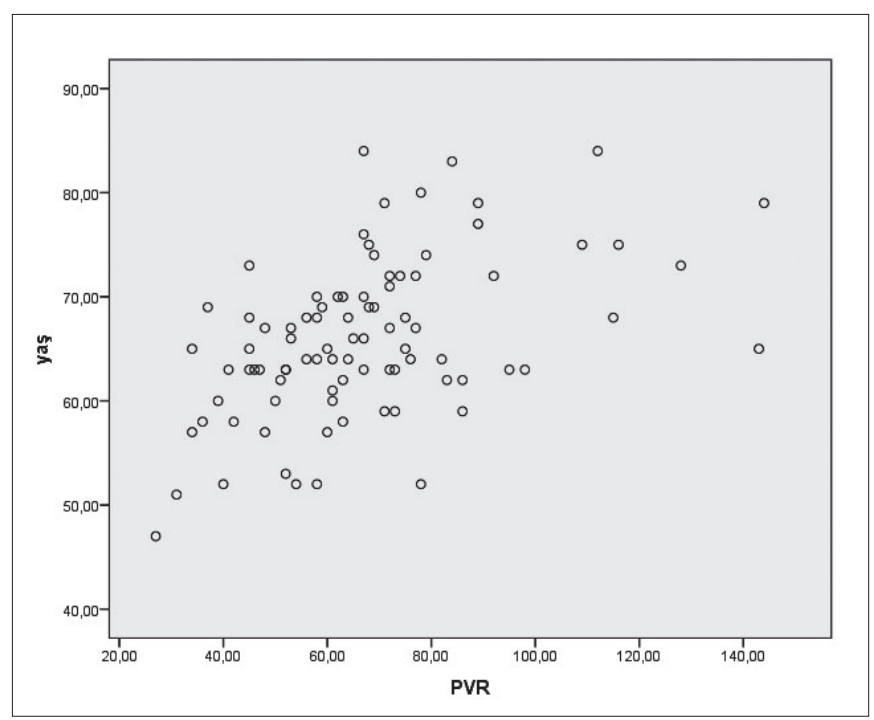

Şekil 1. PVR ile yaş korelasyon grafiği 


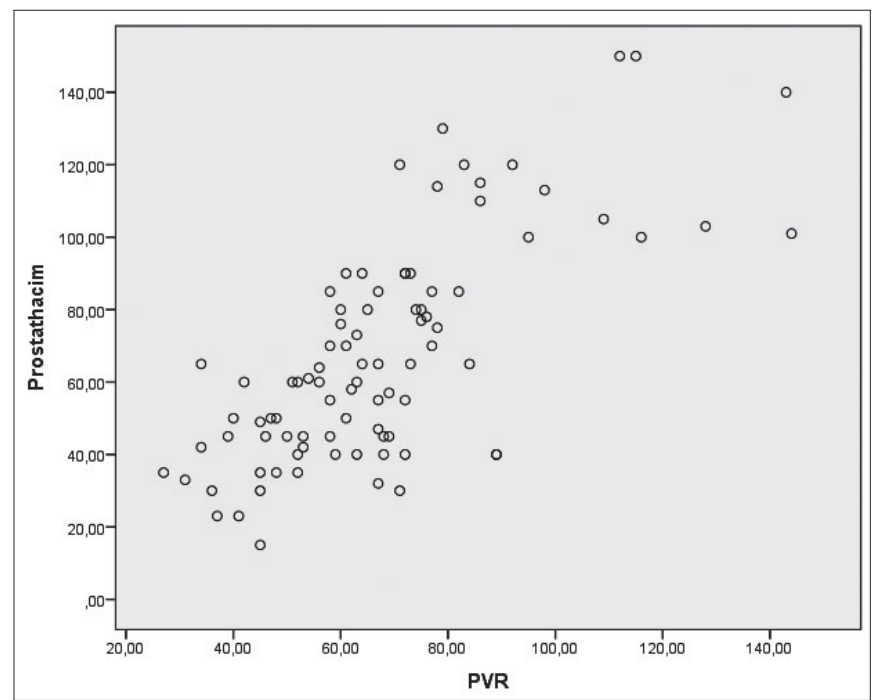

Şekil 2. PVR ile prostat hacmi korelasyon grafiği

\section{TARTIȘMA}

Alt üriner sistem semptomları yaşlanan erkeklerin sık karşılaştığı sorunlardan biridir. Yapılan bir çalışmada çoğunluğu 56-75 yaşında olan 1535 erkekte yavaş akım, işeme sonrası damlama ve urgency prevalanslarının sırasıyla \%61, \%55 ve $\% 52$ olduğu bildirilmiştir. ${ }^{[9]}$

İşeme esnasında kabaca üç olay gerçekleşir: intravezikal basınç artar, mesane çıkım direnci düşer ve üretradaki idrar boşaltılır. İntravezikal basınç sakral kordda yerleşik spinal refleksden kaynaklanan koordine detrüsör kası hasılması ile arttırılır. İntravezikal basınca karşı asıl direnç düz kastan oluşan internal sfinkter tarafindan oluşturulur. Pelvik diyafram üzerindeki tüm organlar intrabdominal organlar olarak kabul edildiğinden intravezikal basınç detrüsör basıncının yanı sıra intraabdominal basınçtan da etkilenir. ${ }^{[1]}$

Üroflowmetri ve PVR ölçümü mesane çıkım obstrüksiyonunun değerlendirilmesinde sıklıkla kullanılan yöntemlerdir. ${ }^{[8]}$ Üroflowmetri testi standardize edilmiş bir yöntemdir ve erkeklerde genellikle ayakta işeme pozisyonunda yapılır. Etnik, sosyal, kültürel ya da tıbbi nedenler ile farklı pozisyonlar da denenebilir. Dünya genelinde işeme alışkanlıkları bölgesel olarak değişiklik gösterebilmektedir. ${ }^{[0]}$

İşeme pozisyonunun üroflowmetri parametreleri ve PVR üzerine etkisi konusunda sınırlı sayıda çalışmalar yapılmıştır. ${ }^{[3-6,10-12]}$ Sağlıklı 66 genç erkekle yapılan ve işeme pozisyonunun üroflowmetri parametreleri ve PVR üzerine etkisini araştıran bir çalışmada oturur pozisyonda işemede ayakta ve çömelerek işemeye göre idrar akım hızının daha düşük olduğu ve işeme süresi daha uzun olduğu bulunmuştur. PVR değerleri ise her üç pozisyonda benzer olarak bulunmuştur (ayakta işeme sonrası PVR: 4,9 $93,6 \mathrm{~mL}$, oturarak işeme sonrası PVR: $6,4 \pm 6,7 \mathrm{~mL}$, çömelerek işeme sonrası PVR: $5,3 \pm 4,5 \mathrm{~mL}, \mathrm{p}>0,05) .{ }^{[10]}$ Oturarak işemedeki düşük idrar akım hızı ve uzun işeme süresi intra-abdominal basıncın bu pozisyonda yeterince arttırılamaması ile ilişkili olabilir.

Goel ve arkadaşları, yaş ortalamaları 40,3 yıl olan 740 sağliklı erkek hastada ayakta ve oturarak işemenin üroflowmetri parametreleri üzerine etkisini incelemiş ve 50 yaşın altındaki hastalarda herhangi bir farklılık tespit edilmemiştir. Fakat 50 yaş üzerindeki hastalarda oturarak işeme pozisyonunda PVR ayakta işemeye göre anlamlı derecede düşük izlenirken, işeme süresi ise anlamlı derecede uzun bulunmuştur. ${ }^{[6]} \mathrm{Bu}$ çalı̧smada oturur pozisyonda daha düşük bulunan PVR değişen üretral açı ve pelvik taban kaslarında meydana gelen gevşeme ile ilişkili olabilir.

Güncel çalışmamızda ise istatistiksel olarak anlamlı olmamakla birlikte çömelerek işeyen hastalarda PVR daha yüksek olarak gözlenmiştir ve PVR ile yaş ve prostat hacmi arasında korelasyon saptanmıştır.

Aghamir ve ark. ${ }^{[3]}$ ayakta, çömelerek ve oturarak olmak üzere üç farklı işeme pozisyonunda üroflowmetri ve rezidü idrar parametrelerini sağlıklı gönüllüler ve benign prostat hiperplazili hastalar arasında karşılaştırmıştır. Sağlıklı erkeklerde 3 farklı işeme pozisyonlarında üroflowmetri parametreleri arasında anlamlı farklılık izlenmezken PVR'nin oturur pozisyonda işemede çömelerek ya da ayakta işemeye göre daha az olduğu bulunmuştur, 67 mL'ye karşın 130 $\mathrm{mL}$ ve $130 \mathrm{~mL}(\mathrm{p}<0,001)$. Maksimum akım hızlarının ve toplam işeme süresinin üç farklı pozisyonda benzer olduğunu bulmuşlardır. ${ }^{[3]}$ Bizim çalışmamızda hastaların oturarak işeme sonrası PVR hacimleri ölçülmemiştir. Fakat bahsedilen çalışmada oturarak işeme sonrası daha az olan PVR işeme postürünü sabit tutmak için gerekli olan kas tonusu ile alakalı olabilir.

Riehmann ve ark. tarafından yaklaşı 30 yıl önce yapılan bir çalışmada ortalama yaşı 71,8 yıl olan 53 huzur evi sakini erkek ile yaşları 34 ve 59 olan sağlıklı iki erkeğin ayakta ve yatar poziyondaki üroflowmetri ve PVR parametreleri karşılaştırılmıştır. Sağlıklı erkeklerde yatar ve ayakta pozisyonda işeme sonrası PVR değerleri arasında anlamlı fark saptanmazken, huzur evi sakinleri grubunda PVR değeri yatarak işeme sonrasında ayakta işemeye göre anlaml1 olarak yüksek bulunmuştur ${ }^{8} 4,8 \pm 186,2$ mL'ye karşın $60,5 \pm 125,6 \mathrm{~mL}(\mathrm{p}=0,049)]$.

Erkeklerde işeme sonrası rezidüel idrar hacmi sadece işeme pozisyonu ile ilişkili değildir. Yaşla birlikte büyüyen prostat ve mesanede meydana gelen yapısal değişiklikler işeme parametreleri üzerinde etkili olabilir. 


\section{Kısıtlılıklar}

Bu çalışmamızın elbette kısıtlılıkları bulunmaktadır. Her şeyden önce mesane içi ve işeme esnasındaki basıncı en iyi gösteren yöntem olan ürodinamik incelemeler invazif ve zahmetli tetkikler olduğu için yapılamamıştır. Ayrıca kullanılan üroflowmetri cihazı uygun olmadığından çömelerek işeme esnasında üroflowmetri yapılamamışıır. Fakat çömelerek işeme alışkanlığı olan hastaların ayakta yaptıkları üroflowmetri testi mesanenin durumu ve pozisyon değişikliğinin işeme üzerine etkisi hakkında bir fikir vermesi açııından anlamlı olabilir. Hastalarının vücut kitle indekslerinin analize dahil edilememesi, hastaların eğitim düzeyleri ve bununla ilişkili olabilecek işeme ritüelleri sonuçları etkilemiş olabilir. Son olarak, farklı bir ortamda ve test amaçlı işemesi istenen hastaların yaşayabilecekleri anksiyete işemelerini kötüleştirmiş olabilir.

\section{SONUÇ}

Bu çalışmamızda yaşlı Türk erkek popülasyonunda ayakta ve çömelerek işemenin işeme sonrası mesanede kalan idrar hacmi üzerine herhangi bir etkisinin olmadığı gösterilmiştir. PVR üzerinde etkili olan asıl faktörler prostat hacmi ve yaş olarak bulunmuştur. Sosyokültürel alışkanlıklar dışında ayakta işemeden kaçınılmasını öngören bir kanıt bulunmamaktadır.

\section{Hakem Değerlendirmesi}

Dış bağımsız

Çıkar Çatışması

Yazarlar çıkar ilişkisi olmadığını beyan etmişlerdir.

Finansal Destek

Herhangi bir mali destek alınmamıştır.

\section{Peer-review}

Externally peer-reviewed.

\section{Conflict of Interest}

No conflict of interest was declared by the authors.

Financial Disclosure

No financial disclosure was received.

\section{KAYNAKLAR}

1. Claridge M. The physiology of micturition. Br J Urol 1965;37:6203.

2. Fry C. The physiology of micturition. Women's Health Med 2005;2:53-5. [CrossRef]

3. Aghamir SM, Mohseni M, Arasteh S. The effect of voiding position on uroflowmetry findings of healthy men and patients with benign prostatic hyperplasia. Urol J 2005;2:216-21.

4. Yamanishi T, Yasuda K, Sakakibara R, Hattori T, Minamide M, Yuki T, Ito $\mathrm{H}$. Variation in urinary flow according to voiding position in normal males. Neurourol Urodyn 1999;18:553-7. [CrossRef]

5. Ünsal A, Çimentepe E. Voiding position does not affect uroflowmetric parameters and post-void residual urine volume in healthy volunteers. Scand J Urol Nephrol 2004;38:469-71. [CrossRef]

6. Goel A, Kanodia G, Sokhal AK, Singh K, Agrawal M, Sankhwar S. Evaluation of Impact of Voiding Posture on Uroflowmetry Parameters in Men. World J Mens Health 2017;35:100-6. [CrossRef]

7. Lepor H. Pathophysiology of benign prostatic hyperplasia in the aging male population. Rev Urol 2005;7 Suppl 4:S3-S12.

8. Oelke M, Hofner K, Jonas U, de la Rosette JJ, Ubbink DT, Wijkstra H. Diagnostic accuracy of noninvasive tests to evaluate bladder outlet obstruction in men: detrusor wall thickness, uroflowmetry, postvoid residual urine, and prostate volume. Eur Urol 2007;52:827-34. [CrossRef]

9. Ho LY, Chu PS, Consigliere DT, Zainuddin ZM, Bolong D, Chan $\mathrm{CK}$, et al. Symptom prevalence, bother, and treatment satisfaction in men with lower urinary tract symptoms in Southeast Asia: a multinational, cross-sectional survey. World J Urol 2018;36:7986. [CrossRef]

10. Choudhury S, Agarwal MM, Mandal AK, Mavuduru R, Mete UK, Kumar S, Singh SK. Which voiding position is associated with lowest flow rates in healthy adult men? role of natural voiding position. Neurourol Urodyn 2010;29:413-7. [CrossRef]

11. Riehmann M, Bayer WH, Drinka PJ, Schultz S, Krause P, Rhodes $\mathrm{PR}$, et al. Position-related changes in voiding dynamics in men. Urology 1998;52:625-30. [CrossRef]

12. Yazici CM, Turker P, Dogan C. Effect of voiding position on uroflowmetric parameters in healthy and obstructed male patients. Urol J 2014;10:1106-13. 